\title{
Metal Machining-Recent Advances, Applications, and Challenges
}

\author{
Francisco J. G. Silva
}

Citation: Silva, F.J.G. Metal Machining-Recent Advances, Applications, and Challenges. Metals 2021, 11, 580. https://doi.org/ $10.3390 /$ met11040580

Received: 29 March 2021

Accepted: 31 March 2021

Published: 2 April 2021

Publisher's Note: MDPI stays neutral with regard to jurisdictional claims in published maps and institutional affiliations.

Copyright: (C) 2021 by the author. Licensee MDPI, Basel, Switzerland. This article is an open access article distributed under the terms and conditions of the Creative Commons Attribution (CC BY) license (https:/ / creativecommons.org/licenses/by/ $4.0 /)$.
ISEP-School of Engineering, Polytechnic Institute of Porto, 4249-015 Porto, Portugal; fgs@isep.ipp.pt; Tel.: +351-228340500

\section{Introduction and Scope}

Though new manufacturing processes that revolutionize the landscape regarding the rapid manufacture of parts have recently emerged, the machining process remains alive and up-to-date in this context, always presenting itself as a manufacturing process with several variants and allowing for high dimensional accuracy and high levels of surface finish [1-3]. Indeed, machining has numerous aspects that constantly need to be investigated due to the constant evolution of materials to be machined, the materials and geometry of tools, and the evolution of coatings normally applied to the tools' surfaces [4-6]. In view of this evolution, the parameters used in machining also need to be optimized, thus contributing to increased attention by researchers in this area of manufacturing [7-10]. In fact, metal alloys have significantly evolved in terms of properties, which poses additional challenges for research [11-13]. The market's demand for new alloys that need to meet increasingly demanding requirements is a constant, thus creating a greater diversity of alloys in the market and new challenges in their processing in order to achieve the characteristics required by customers. When the requirements are truly challenging, it becomes necessary to make polymeric or metallic matrix composite materials, creating even more demanding challenges in their processing that have further expanded the research field in the machining area [14-16]. Composite materials still have a huge margin of progression in terms of research, which will also allow the scientific community linked to the manufacturing processes to continue to have a lot of available topics to explore. For example, the chip that can be formed during the machining processes has been the subject of several studies because chip formation provides valuable and useful information about the way the machining process is being conducted and can provide information on the problems related to its removal from equipment and occupied space [17-19]. Dry machining has always been a great challenge [20] because lubrication causes environmental problems [21] and, in some cases, is not even allowed. Thus, aspects related to lubrication in machining have also been widely explored by using techniques that seek to minimize the use of lubrication (minimum quantity lubrication) [22,23]. On the other hand, the need to increase productivity levels has not only resorted to the science of materials and technological processes to offer the industry the necessary means to produce with the necessary quality at increasingly competitive costs but also captured the attention of the industrial engineering field [24,25]. This has led to numerous research projects aimed at the development of models and procedures that allow for the optimization of all operations involving machining processes, as well as some tools used in the process itself, such as more advanced jigs [26].

Recently, new research opportunities have opened up because machining operations are largely linked to the concepts of Industry 4.0. In fact, the operations traditionally developed between equipment can be integrated by using computer systems with greater decision power, making the whole production process much more agile $[27,28]$. The concepts of Industry 4.0 have also made it possible to develop other areas around machining, namely the concept of "machine learning," which allows for the creation of standard figures 
that can be recognized by equipment and thus allowing for greater integration between CAD (Computer-Aided Design) and CAM (Computer-Aided Manufacturing) [29,30]. Similarly, the measurement operations of tools and machined parts bring new challenges that are also being scientifically explored [31]. The vibration index and cutting forces developed in tools, which naturally evolve with wear, can also be properly monitored to bring added information to the process and allow for the automation of tool change decisions or maintenance interventions for equipment $[32,33]$.

Bearing in mind all the previously mentioned factors, it is easy to realize that there is innumerable research to be continuously developed in this field of investigation. Thus, this Special Issue intended to gather contributions from different authors in the field of machining, allowing for its easy dissemination and thus contributing to an increase of knowledge of the scientific community that works hard in this area.

\section{Contributions}

The contributions received for this Special Issue are high-quality and show how active the research around machining processes is. Three of the studies contained in this Special Issue are related to the chip formation and cutting behavior that are registered during the machining process. In the work "Assessment of Chip Breakability during Turning of Stainless Steels Based on Weight Distributions of Chips" developed by Du et al. [34], the breakability of the stainless-steel chip is studied in the turning of these alloys by using a new methodology: the weight distribution of chips. This methodology was shown to present very consistent results in the evaluation of the way a part is trimmed, thus allowing one to perceive the machinability of a given alloy and allowing for a comparison with similar ones. The study was developed on an AISI 316L alloy, using one without treatment and another with treatment and showing that the treatment drastically modified the breakability of the chip. Even though the chip looked very similar for both cases, the developed method showed that the obtained results were significantly different, showing how this methodology can be useful in other analyses. On the other hand, the work entitled "Predicting Continuous Chip to Segmented Chip Transition in Orthogonal Cutting of C45E Steel through Damage Modeling" performed by Devotta et al. [35] integrated dynamic strain aging in the Johnson-Cook model, which is usually used to modelling machining processes, while also using the Voyiadjis-Abed-Rusinek approach. In this way, it became possible to predict the transition from a continuous chip to a discontinuous chip regarding the widely used C45E steel, depending on the rake angle and feed rate while keeping the cutting speed constant. The main outcome of the study was to discover that chip segmentation intensity and frequency are sensitive to fracture initiation strain models. Additionally, using the finite element method, but now based on an AA2024 T351 aluminum alloy, Muhammad Asad [36] studied the influence of the tool's geometry, namely hone and chamfer, on chip segmentation and burr formation. The study demonstrated an increasing trend in the degree of chip segmentation and end burr as hone edge tool radius or chamfer tool geometry macro parameters concerning chamfer length and angle increased. With the development of this work, a model that helps in the definition of the best tool geometry and the optimization of the cutting parameters was obtained, with the aim to increase productivity, minimize the formation of burr, and avoid the formation of a continuous chip. The quality of a machined surface is also present in this Special Issue. In order to minimize the problems reported in the quality of finishing of aluminum parts, Rubio-Mateos et al. [37] studied the introduction of elastomeric systems to support parts to be machined, with a view to dampening any vibrations during the finishing process of soft materials. For this, nitrile butadiene rubber (NBR) was used. A suitable flexible vacuum fixture was also developed, allowing for the easy implementation of the system in the manufacturing process. Different sets of parameters that varied the degree of compression imposed on the flexible system were tested, verifying that it perfectly accommodated these variations. Thus, the main outcome of this work was the establishment that the milling operations of the AA2024 alloy can benefit from more flexible fixations to the 
detriment of very rigid jigs. Del Sol and Rivero [38] also investigated the parameters that could give rise to skin panel and thin plate components obtained by machining, thus eliminating the need to use chemical milling in the manufacture of parts for the aeronautical industry because the rigidity presented for this type of parts is quite low. The study was essentially conducted by using the experimental pathway, measuring the cutting forces that developed during the process and keeping the surface roughness within the imposed limits. The correct selection of the cutting parameters led to a $40 \%$ reduction in the thickness variation of the components and a $20 \%$ decrease in the cutting forces, which makes the clamping process of parts easier. The study also resulted in the creation of a model capable of monitoring the quality of the process based on the measurement of equipment power consumption. The work of Berzosa et al. [39], entitled "Feasibility Study of Hole Repair and Maintenance Operations by Dry Drilling of Magnesium Alloy UNS M11917 for Aeronautical Components," also investigated the best set of parameters to be used for drilling holes in magnesium alloys, which are increasingly used in the aeronautical, aerospace, and even automotive industries. The study of the parameters allowed for an improvement of the surface quality obtained in holes made in that alloy, mainly in repair or maintenance operations. Additionally, based on the aeronautical industry, Martín Béjar et al. [40] investigated the macro-geometric deviations reported in the turning of a UNS A97075 alloy, verifying that the parts provided with a lower stiffness presented a greater sensitivity to macro dimensional deviations when adjusting parameters. It was once again verified that feed speed is the parameter with the greatest influence on the deviations recorded during the turning process. Based on the obtained results, models that allow for the prediction of macro dimensional deviations as a function of machining parameters were presented. Bañon et al. [41] carried out a quality study of the cut surface in structures composed of different materials. In that case, the abrasive waterjet cutting of a mixed structure of CFRTP (carbon fiber-reinforced thermo-plastic) with steel was studied, which presented quite different behaviors under the same cutting conditions. Two different stacking configurations were studied to investigate different sets of parameters that would lead to lower levels of roughness in waterjet cutting when using abrasives. The experimental work made it possible to draw several diagrams that enabled the correlation of the cutting parameters with the cut surfaces' quality. The sustainability related to the machining processes is also represented in this Special Issue. Indeed, sustainability can be explored in its most diverse aspects because productivity is fundamental but environmental impact-with important factors such as power consumption, the minimum use of lubricants/coolants, and social issues in which health conditions at work and ergonomics must be respected-cannot be ignored. Iqbal et al. [42] investigated the use of cryogenic coolants in the machining of the Ti6Al4V alloy, which is widely used in aeronautics. At the same time, they tried to optimize the parameters with a view to minimizing the consumption of tools by acting on the parameters of the milling process. As main outcomes, it was found that micro-lubrication was more effective than cryogenic cooling with $\mathrm{CO}_{2}$ or liquid nitrogen; it could increase tool life while also improving the surface quality of machined parts, reducing energy consumption, and reducing the overall cost of process. These authors also verified that the high levels of cutter's helix angle and cutting speed clearly contributed to an increase in process sustainability. Diaz-Álvarez et al. [43] also investigated new cutting parameters in the turning of the Haynes 282 nickel alloy while avoiding the use of lubricants/coolants. The used coated tools allowed them to optimize the cutting parameters, making it possible to obtain roughness values in the machined parts as low as those obtained using lubricants/coolants. The proper selection of parameters also kept the cutting forces as low as those obtained with lubrication, as well as extending the tools' life. In this way, the process can become more environmentally sustainable without jeopardizing product quality or economic sustainability.

In addition to the aforementioned works, this Special Issue also presents two widerevision works $[5,8]$, one on the use of coated tools in turning and another that performs an in-depth study of the literature on TiAlN-based coatings for both the turning and 
milling processes, focusing on coatings developed around that same coating, providing information on recent uses of these coatings and what elements are used in the fabrication of these types of coatings, showing their mechanical properties, and providing information on their machining performance and application. Each of the reviews is based on more than one hundred references, thus allowing for the deepening and discussing of innumerable ideas taken from a wide range of works. These works constitute a great base of work for MSc and PhD students who are starting in the area by providing (in a concentrated way) a wide range of knowledge in these areas, from the cutting performance of various coated tools in machining processes to the study of the different wear patterns and mechanisms that these tools suffer during the machining process.

\section{Conclusions and Outlook}

Through the research collected in this Special Issue, it can be noted that there is much work regarding the machining process, in its most diverse aspects, to be continuously carried out because there is still a huge margin of progression in almost all aspects of machining. In this Special Issue, some excellent examples of the most recent developments in this area are shown, with special emphasis given to optimizing parameters, increasing the quality of machined surfaces, and improving the sustainability of the process. Very important information is also provided regarding tool coatings, with a view to extending cutting tools' working life, which will certainly be useful for those who conduct research in this area or for young students who want to start their studies in this field of knowledge.

The continuous search for greater productivity in machining and for increases of tools working life (always based on the improvement of the global sustainability) will lead to more and more research in this area that will continue to be collected and disseminated, thus allowing this process to continue to be competitive and capable of producing high-quality parts. Thus, the research around machining processes will surely remain challenging.

Conflicts of Interest: The author declares no conflict of interests.

\section{References}

1. Rathod, V.; Doloi, B.; Bhattacharyya, B. Experimental investigations into machining accuracy and surface roughness of microgrooves fabricated by electrochemical micromachining. Proc. Inst. Mech. Eng. Part B J. Eng. Manuf. 2014, 29, 1781-1812. [CrossRef]

2. Kwon, S.B.; Nagaraj, A.; Yoon, H.S.; Min, S. Study of material removal behavior on R-plane of sapphire during ultra-precision machining based on modified slip-fracture model. Nanotechnol. Precis. Eng. 2020, 3, 141-155. [CrossRef]

3. Wang, J.; Fu, J.; Wang, J.; Du, F.; Liew, P.J.; Shimada, K. Processing capabilities of micro ultrasonic machining for hard and brittle materials: SPH analysis and experimental verification. Precis. Eng. 2020, 63, 159-169. [CrossRef]

4. Martinho, R.P.; Silva, F.J.; Baptista, A.P.M. Cutting forces and wear analysis of $\mathrm{Si}_{3} \mathrm{~N}_{4}$ diamond coated tools in high speed machining. Vacuum 2008, 82, 1415-1420. [CrossRef]

5. Sousa, V.F.; Silva, F.J.G.; Alexandre, R.; Fecheira, J.S.; Silva, F.P.N. Study of the wear behaviour of TiAlSiN and TiAlN PVD coated tools on milling operations of pre-hardened tool steel. Wear 2021, 203695. [CrossRef]

6. Kumar, R.; Singh, S.; Bilga, P.S.; Jatin, K.; Singh, J.; Singh, S.; Scutaru, M.-L.; Pruncu, C.I. Revealing the benefits of entropy weights method for multi-objective optimization in machining operations: A critical review. J. Mater. Res. Technol. 2021, 10, 1471-1492. [CrossRef]

7. Sousa, V.F.C.; Silva, F.J.G. Recent Advances on Coated Milling Tool Technology_A Comprehensive Review. Metals 2020, 10, 235. [CrossRef]

8. Sousa, V.F.C.; Silva, F.J.G. Recent Advances in Turning Processes Using Coated Tools-A Comprehensive Review. Metals 2020, 10, 170. [CrossRef]

9. Sousa, V.F.C.; Da Silva, F.J.G.; Pinto, G.F.; Baptista, A.; Alexandre, R. Characteristics and Wear Mechanisms of TiAlN-Based Coatings for Machining Applications: A Comprehensive Review. Metals 2021, 11, 260. [CrossRef]

10. Pangestu, P.; Pujiyanto, E.; Rosyidi, C.N. Multi-objective cutting parameter optimization model of multi-pass turning in CNC machines for sustainable manufacturing. Heliyon 2021, 7, e06043. [CrossRef]

11. Tanaka, H.; Kitamura, M.; Sai, T. An Evaluation of Cutting Edge and Machinability of Inclined Planetary Motion Milling for Difficult-to-cut Materials. Procedia CIRP 2015, 35, 96-100. [CrossRef]

12. Martinho, R.P.; Silva, F.J.G.; Martins, C.; Lopes, H. Comparative study of PVD and CVD cutting tools performance in milling of duplex stainless steel. Int. J. Adv. Manuf. Technol. 2019, 102, 2423-2439. [CrossRef] 
13. Gouveia, R.M.; Silva, F.J.G.; Reis, P.; Baptista, A.P.M. Machining Duplex Stainless Steel: Comparative Study Regarding End Mill Coated Tools. Coatings 2016, 6, 51. [CrossRef]

14. Sun, W.; Duan, C.Z.; Yin, W.D. Chip formation mechanism in machining of Al/SiCp composites based on analysis of particle damage. J. Manuf. Processes 2021, 64, 861-877. [CrossRef]

15. Chen, Z.; Zhou, H.; Yan, Z.; Han, F.; Yan, H. Machining characteristics of 65 vol.\% SiCp/Al composite in micro-WEDM. Ceram. Int. 2021. in Press. [CrossRef]

16. Khan, M.A.; Jani, S.P.; Kumar, A.S.; Rajesh, S. Machining parameter optimization using Adam-Gene Algorithm while turning lightweight composite using ceramic cutting tools. Int. J. Lightweight Mater. Manuf. 2021, 4, 262-267. [CrossRef]

17. Chen, X.; Tang, J.; Ding, H.; Liu, A. A new geometric model of serrated chip formation in high-speed machining. J. Manuf. Processes 2021, 62, 632-645. [CrossRef]

18. Silva, F.J.G.; Martinho, R.P.; Martins, C.; Lopes, H.; Gouveia, R.M. Machining GX2CrNiMoN26-7-4 DSS Alloy: Wear Analysis of TiAlN and TiCN $/ \mathrm{Al}_{2} \mathrm{O}_{3} / \mathrm{TiN}$ Coated Carbide Tools Behavior in Rough End Milling Operations. Coatings 2019, 9, 392. [CrossRef]

19. Arefin, S.; Zhang, X.; Kumar, A.S.; Neo, D.W.K.; Wang, Y. Study of chip formation mechanism in one-dimensional vibrationassisted machining. J. Mater. Process. Technol. 2021, 291, 117022. [CrossRef]

20. Cavaleiro, D.; Figueiredo, D.; Moura, C.W.; Cavaleiro, A.; Carvalho, S.; Fernandes, F. Machining performance of TiSiN(Ag) coated tools during dry turning of TiAl6V4 aerospace alloy. Ceram. Int. 2021, 47, 11799-11806. [CrossRef]

21. Silva, F.J.G.; Gouveia, R.M. Cleaner Production—Toward a Better Future; Springer Nature: Cham, Switzerland, 2020; ISBN 978-3-03023164-4.

22. Hamran, N.N.N.; Ghani, J.A.; Ramli, R.; Haron, C.H.C. A review on recent development of minimum quantity lubrication for sustainable machining. J. Clean. Prod. 2020, 268, 122165. [CrossRef]

23. García-Martínez, E.; Miguel, V.; Manjabacas, M.C.; Martínez-Martínez, A.; Naranjo, J.A. Low initial lubrication procedure in the machining of copper-nickel 70/30 ASTM B122 alloy. J. Manuf. Processes 2021, 62, 623-631. [CrossRef]

24. Monteiro, C.; Ferreira, L.P.; Fernandes, N.O.; Sá, J.C.; Ribeiro, M.T.; Silva, F.J.G. Improving the machining process of the metalworking industry using the lean tool SMED. Procedia Manuf. 2019, 41, 555-562. [CrossRef]

25. Martins, M.; Godina, R.; Pimentel, C.; Silva, F.J.G.; Matias, J.C. A Practical Study of the Application of SMED to Electron-beam Machining in Automotive Industry. Procedia Manuf. 2018, 17, 647-654. [CrossRef]

26. Kumar, S.; Campilho, R.D.S.G.; Silva, F.J.G. Rethinking modular jigs' design regarding the optimization of machining times. Procedia Manuf. 2019, 38, 876-883. [CrossRef]

27. Mehdi, N.; Starly, B. Witness Box Protocol: Automatic machine identification and authentication in industry 4.0. Comput. Ind. 2020, 123, 103340. [CrossRef]

28. Barbosa, M.; Silva, F.J.G.; Pimentel, C.; Gouveia, R.M. A Novel Concept of CNC Machining Center Automatic Feeder. Procedia Manuf. 2018, 17, 95-959. [CrossRef]

29. Barton, D.; Gönnheimer, P.; Schade, F.; Ehrmann, C.; Becker, J.; Fleischer, J. Modular smart controller for Industry 4.0 functions in machine tools. Procedia CIRP 2019, 81, 1331-1336. [CrossRef]

30. Ulas, M.; Aydur, O.; Gurgenc, T.; Ozel, C. Surface roughness prediction of machined aluminum alloy with wire electrical discharge machining by different machine learning algorithms. J. Mater. Res. Technol. 2020, 9, 12512-12524. [CrossRef]

31. Alonso, V.; Dacal-Nieto, A.; Barreto, L.; Amaral, A.; Rivero, E. Industry 4.0 implications in machine vision metrology: An overview. Procedia Manuf. 2019, 41, 359-366. [CrossRef]

32. Sousa, V.F.C.; Silva, F.J.G.; Fecheira, J.S.; Lopes, H.M.; Martinho, R.P.; Casais, R.B.; Ferreira, L.P. Cutting Forces Assessment in CNC Machining Processes: A Critical Review. Sensors 2020, 20, 4536. [CrossRef]

33. Costa, S.; Silva, F.J.G.; Campilho, R.D.S.G.; Pereira, T. Guidelines for Machine Tool Sensing and Smart Manufacturing Integration Procedia Manuf. 2020, 51, 251-257. [CrossRef]

34. Du, H.; Karasev, A.; Björk, T.; Lövquist, S.; Jönsson, P.G. Assessment of Chip Breakability during Turning of Stainless Steels Based on Weight Distributions of Chips. Metals 2020, 10, 675. [CrossRef]

35. Moris Devotta, A.; Sivaprasad, P.V.; Beno, T.; Eynian, M. Predicting Continuous Chip to Segmented Chip Transition in Orthogonal Cutting of C45E Steel through Damage Modeling. Metals 2020, 10, 519. [CrossRef]

36. Asad, M. Effects of Tool Edge Geometry on Chip Segmentation and Exit Burr: A Finite Element Approach. Metals 2019, 9, 1234. [CrossRef]

37. Rubio-Mateos, A.; Rivero, A.; Ukar, E.; Lamikiz, A. Influence of Elastomer Layers in the Quality of Aluminum Parts on Finishing Operations. Metals 2020, 10, 289. [CrossRef]

38. Del Sol, I.; Rivero, A.; Gamez, A.J. Effects of Machining Parameters on the Quality in Machining of Aluminium Alloys Thin Plates. Metals 2019, 9, 927. [CrossRef]

39. Berzosa, F.; de Agustina, B.; Rubio, E.M.; Davim, J.P. Feasibility Study of Hole Repair and Maintenance Operations by Dry Drilling of Magnesium Alloy UNS M11917 for Aeronautical Components. Metals 2019, 9, 740. [CrossRef]

40. Martín Béjar, S.; Trujillo Vilches, F.J.; Bermudo Gamboa, C.; Sevilla Hurtado, L. Parametric Analysis of Macro-Geometrical Deviations in Dry Turning of UNS A97075 (Al-Zn) Alloy. Metals 2019, 9, 1141. [CrossRef]

41. Bañon, F.; Simonet, B.; Sambruno, A.; Batista, M.; Salguero, J. On the Surface Quality of CFRTP/Steel Hybrid Structures Machined by AWJM. Metals 2020, 10, 983. [CrossRef] 
42. Iqbal, A.; Suhaimi, H.; Zhao, W.; Jamil, M.; Nauman, M.M.; He, N.; Zaini, J. Sustainable Milling of Ti-6Al-4V: Investigating the Effects of Milling Orientation, Cutter's Helix Angle, and Type of Cryogenic Coolant. Metals 2020, 10, 258. [CrossRef]

43. Díaz-Álvarez, A.; Díaz-Álvarez, J.; Cantero, J.L.; Miguélez, H. Sustainable High-Speed Finishing Turning of Haynes 282 Using Carbide Tools in Dry Conditions. Metals 2019, 9, 989. [CrossRef] 